\title{
THE USE OF DISCRETE EVENT SIMULATION IN A DESIGN FOR SIX SIGMA PROJECT
}

\author{
Michael J. Seifert \\ Group Manager, ICCOS \\ Capital One Services, Inc. \\ 15000 Capital One Drive \\ Richmond, Va 23238 U.S.A
}

\begin{abstract}
This paper describes how a risk event to customer satisfaction for a food service facility was identified, validated, and eventually mitigated through the use of a discrete event simulation as part of a Design for Six Sigma project. Further described is how simulation was utilized to identify leading indicators to the risk event, to give pre-warning of the occurrence as well as to perform what if tests to validate mitigation practices and contingency plans. The results presented demonstrate how a simulation model coupled with Six Sigma can design a superior process in regards to predictability and reliability.
\end{abstract}

\section{INTRODUCTION}

Capital One Financial Services Corporation experienced substantial growth during the 1990's. A rapidly growing workforce drove expansion into over 30 buildings spread across the city of Richmond Virginia. A result of this highly decentralized workforce was that training, communication, and day-to-day meetings became increasingly difficult and expensive to manage. The decision was made to consolidate employees into a new campus on the outskirts of Richmond, centered around a best in class Town Center.

The Town Center was designed to be a cutting edge training and conference center. It would house Capital One University and provide all manner of training from IT programming to performance management. In addition, a wide range of conference rooms would be equipped with audiovideo and communications equipment.

Capital One also required that high quality, efficient food services be an integral part of the Town Center. A "Lodge" area was created to deliver a feel and appearance intended to exceed any outside professional conferencing center in regards to meals. Professional consultants and contractors were hired to help design and eventually manage and run the Town Center and "Lodge". The consultants had extensive experience in similar operations in both private and governmental facilities.
While the contractors hired to manage and run the "Lodge" had extensive experience, the Lodge was being designed to give a different experience than typically observed at other facilities. For example, small food portions would encourage patrons to sample from multiple types of food. This in turn would result in patrons transitioning at a higher rate between multiple food bars and spending more time contemplating what to try.

These "new" aspects being employed in the Lodge design meant that the team could not fully assess risk events from past designs and processes. Therefore it was decided to utilize tools from Six Sigma to identify potential risks, assess their significance, and finally develop mitigation techniques. The particular tools utilized were an FMEA (Failure Modes and Effects Analysis) to identify potential risks and simulation to determine the validity and significance of these risks, as well as test out mitigation plans. This was to be conducted before the Town Center and Lodge ever opened.

In section 2, an overview of the Design for Six Sigma Methodology is provided. In section 3, the Design for Six Sigma methodology is applied to the Lodge, and a key risk to the success of the Lodge is identified. A discrete event simulation model used in the design and verify phases is described in section 4 . The results and how they were used to change the design is provided in section 5, and the summary and conclusion are provided is section 6 .

\section{DESIGN FOR SIX SIGMA}

DFSS is comprised of 5 phases or steps shown below. The initial three phases focus heavily on understanding customer requirements and identifying what level of performance is required to satisfy and even delight the customer. Once this is understood the design phase is conducted followed by the verify phase.

In the definition phase the objectives surround defining the project and scope while also identifying constraints and risk. 
In the measurement phase, the object is the voice of the customer. In this phase the team gains an understanding of the customer's needs and wants. Those needs and wants are then translated in to requirements or CTQs (Critical to Quality) and prioritized.

In the analyze phase key functions are identified and concepts generated and evaluated. The objective is to select the necessary functions and most viable concepts for likely success.

There are three high level deliverables from the design phase. The first deliverable is the design of the proposed process. Second is a test design to predict the processes performance and the actual conduct of the test. Third, preparation is made for a pilot and full scale deployment.

Finally in the verify phase the main objective is to verify the design's performance and make corrections where needed. Further control plans are often created for the next step of full deployment.

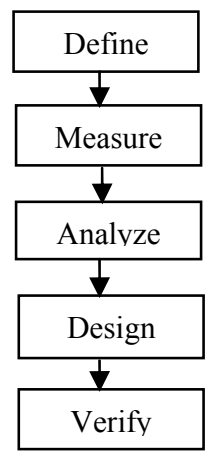

Figure 1: Design for Six Sigma Phases

\section{THE RISK EVENT / FAILURE MODE}

During the design phase a risk event / failure mode was identified through the use of a modified FMEA (Failure Modes and Effects Analysis). The risk identified was the potential for customers of the Lodge to take longer than 45 minutes to be processed through a meal.

The target of 45 was established as a CTQ (critical to quality) attribute for customer satisfaction in the earlier Six Sigma Phases. The 45 minutes assumed that any class or conference would grant a 60 minute break for a meal. Fifteen minutes of that 60 would be utilized for checking voicemail, email, restroom break, etc. This would allow a remainder of 45 minutes for the customer to get their food and beverage and enjoy a 30 minute period of eating, discussion, and networking. The 30 minute seating period was also established as a CTQ for the process. Not that every customer would take advantage of this, but if less than 30 minutes were available to the customer in which to network and enjoy the meal, then customer satisfaction would suffer.

Figure 2 portrays the basic Lodge design and flow.

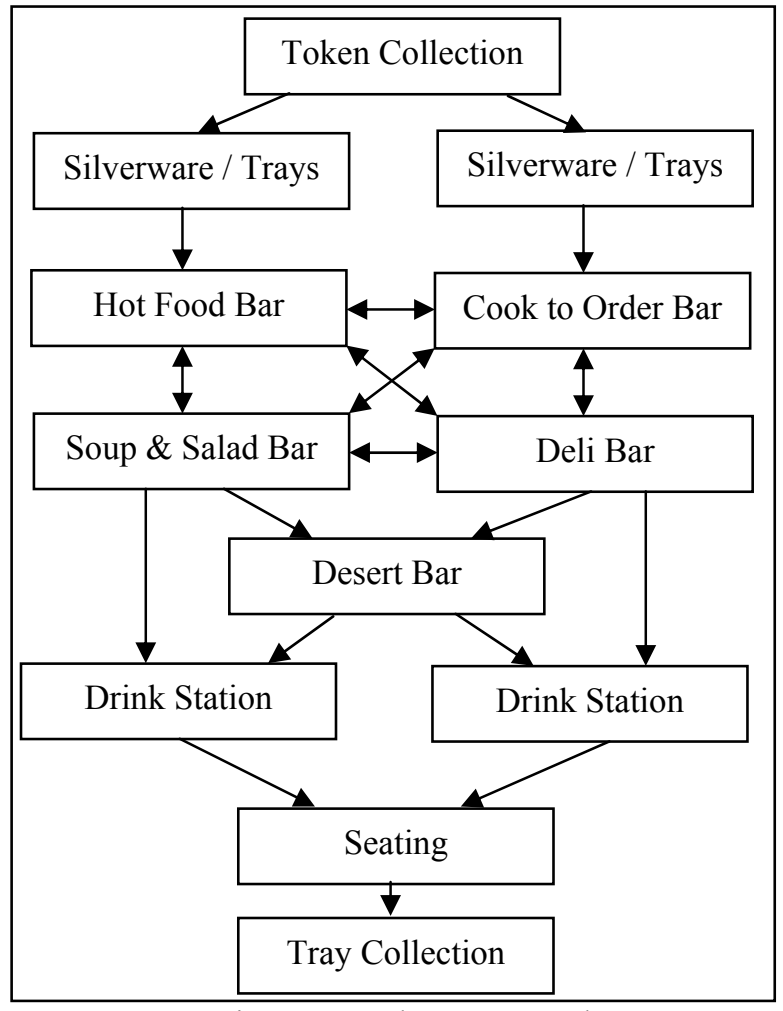

Figure 2: Lodge Process Flow

Initial operating procedures and rules had been proposed for the Town Center and Lodge. For example: Any event in the Town Center lasting 4 or more hours was offered lunch in the Lodge. Each room was assigned a time at which they were allowed to enter the Lodge. The times were established in $3 / 4$ hour intervals with the first interval starting at $11 \mathrm{am}$ and the last interval starting at 12:30 pm.

Each patron was given a token with the time slot indicated on it. The token was to be collected at the entrance to the food stations in the Lodge and this essentially controlled admittance to only those attending Town Center events.

The following sequence of flow is typical in the Lodge:

1. Turn in token to attendant.

2. Obtain tray and silverware.

3. Move among the multiple food bars an select desired food.

4. Depart food area through a Drink / Beverage Station.

5. Consume meal in seating area.

6. Turn is tray, dishes, and silverware in tray collection area.

The initial operating rules set for the Lodge and Town Center were the following: 
1. No outside catering allowed

2. All meals restricted to the Lodge.

This meant that all patrons of the Town Center must be serviced inside the Lodge if they desired food.

The Town center was comprised of 46 rooms of various potential headcounts. In fact by combining certain rooms maximum occupancy levels could change. Patron levels to the Lodge were expected to average $67 \%$ of normal occupancy and $39 \%$ of maximum occupancy.

So the key question became, could the Lodge, under these conditions, service all patrons within 45 minutes?

\section{SIMULATION MODEL}

Discrete Event Simulation was chosen as the key question required assessment of process cycle time and queuing time. Simul8 by Simul8 Corporation was selected due to its ease of use and ability to deploy the model for future operational use at no cost via Simul8's Viewer.

In the first phase of the simulation process, the flow of the Lodge was defined and data estimates established by subject matter experts. Table 1 along with Figures 3 and 4 outline the key data elements used as inputs. This type of estimating had to be handled for each entity of the flow represented in the simulation in Figure 5.

Table 1: Data Elements Measured or Estimated

\begin{tabular}{|c|l|}
\hline & Data Element \\
\hline 1 & Probability that a room is occupied \\
\hline 2 & Number of Occupants likely in a room \\
\hline 3 & Time Slot for Meal for Rooms \\
\hline 4 & $\begin{array}{l}\text { Time Slot Variability: Delay from Start of Time Slot } \\
\text { as to when the room releases (Uniform or Triangular) }\end{array}$ \\
\hline 5 & Number of positions for customers at each bar \\
\hline 6 & Service Times for customers at each bar / station \\
\hline 7 & Probability Profile of Number of Bars Visited \\
\hline 8 & $\begin{array}{l}\text { Probability that a patron will go to the beverage sta- } \\
\text { tion }\end{array}$ \\
\hline 9 & Number of porters available to clean tables \\
\hline 10 & Cleaning and Service Time Distributions \\
\hline 11 & What size groups receive in room catering \\
\hline
\end{tabular}

While the subject matter experts knew prior data for other facilities, the new aspects meant that their prior experiences and data where not fully applicable to this model. However, they used their prior experience of patron's typical behavior as a basis to create estimations. Additionally the team chose to use triangular distributions for the incorporation of variability.

Microsoft Excel spreadsheets where utilized as the data input mechanism. These sheets were then read into the simulation and the simulation runs / trials performed. Below are shown the actual MS Excel Spreadsheets as well as the Simul8 model.

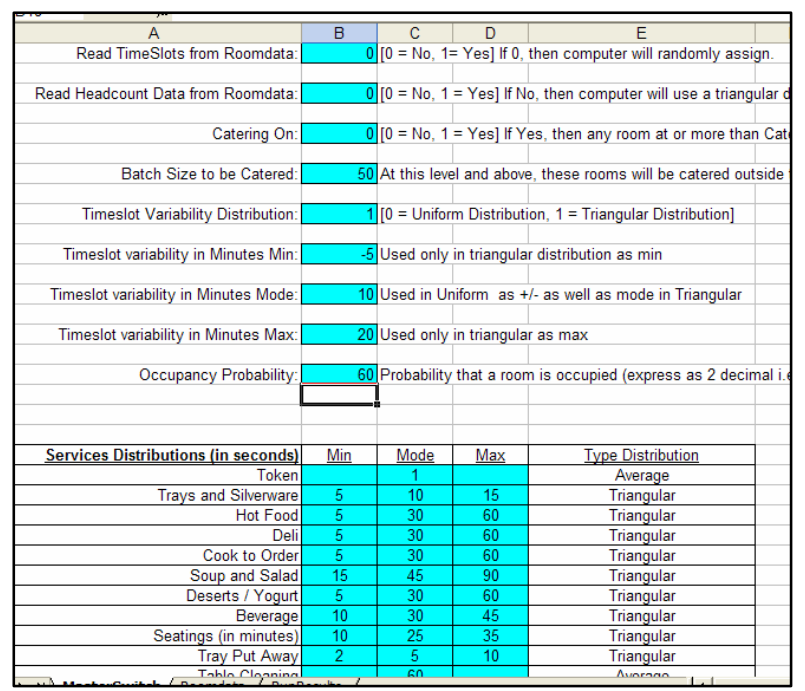

Figure 3: Main Data Input Page

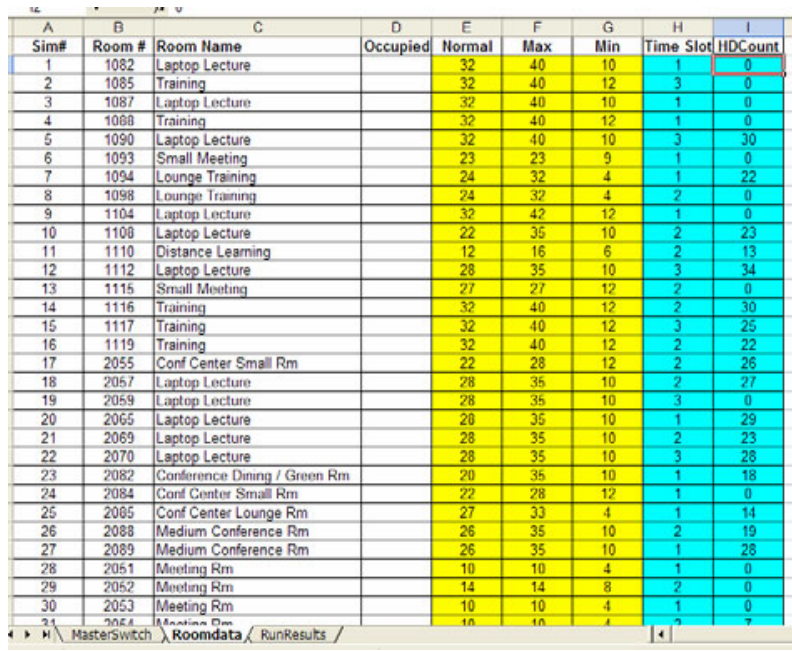

Figure 4: Room Occupancy Input Page

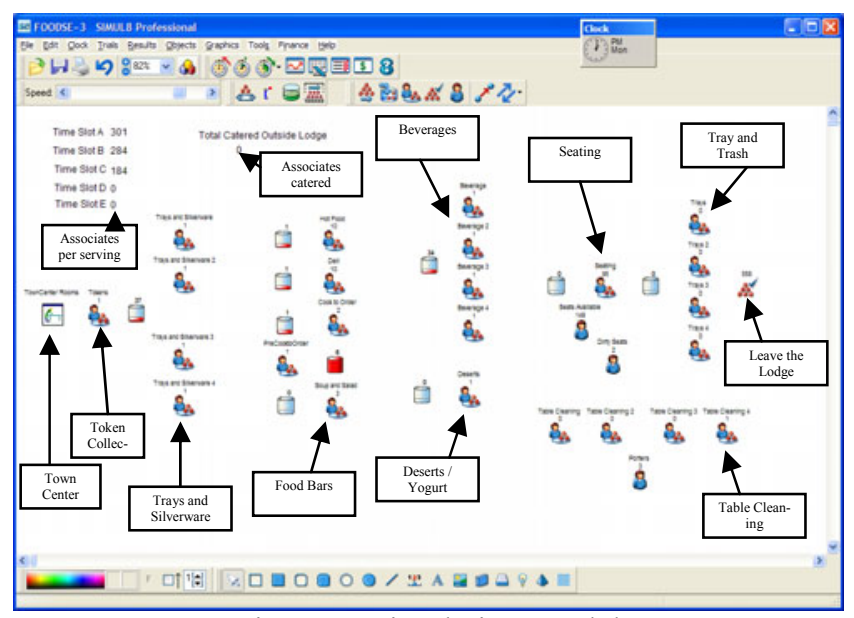

Figure 5: Simulation Model 


\section{SIMULATION RESULTS UTILIZED AS AN ITERATIVE PROCESS TO MITIGATE RISK}

After running trials on the simulation, consisting of a minimum of 30 runs per trial, a confidence interval of $95 \%$ was established for the average maximum time in the Lodge and is shown in Table 2. Keeping in mind the Lodge wanted to target all patrons processed in 45 minutes inclusive of a 30 minute sitting period.

Table 2: Results of Initial Simulation Trial (Minutes)

\begin{tabular}{|l|c|c|c|}
\hline Process & Lower 95\% & Average & Upper 95\% \\
\hline Max Time & 57.22 & 60.78 & 64.35 \\
\hline Avg Time & 33.32 & 34.68 & 36.04 \\
\hline
\end{tabular}

Based on this data, it was determined that if the current assumptions were correct and the currently planned practices were to be implemented, then the Lodge would experience the identified risk event on a daily basis.

The next step was to use the simulation data to identify where the time traps were in the process. The assumption was made that no patrons will abandon a lengthy process. If they did then it was assumed dissatisfaction would result and this would be an unsatisfactory condition in the model. To handle this, it was decided not to use an expiration time for patron wait within queues, thus enabling a Pareto chart comparison for time trap identification. However this also meant the model could create some unrealistic conditions; that of customers waiting for unrestricted amounts of time.

A Pareto of average queue times was created and this identified the beverage stations as the largest contributor to total process time (outside the seating constraint time) and is shown in Table 3.

The drink / beverage station was designed as a typical fountain style self-serve setup. At each station, typically two patrons at a time can obtain a glass, fill the glass with ice, and then dispense the desire beverage from an assortment of fountain heads.

Table 3: Maximum Queue Time for Beverage Station (Minutes)

\begin{tabular}{|l|c|c|c|}
\hline Beverage & Lower 95\% & Average & Upper 95\% \\
\hline Max Time & 17.99 & 20.72 & 23.44 \\
\hline Avg Time & 6.09 & 7.17 & 8.26 \\
\hline
\end{tabular}

Based on this queuing data, strategies were created to alleviate the queue times. For example the following proposals were made:

1. Change from self-service fountain drinks to fast pass beverage lines (similar to stadium and amusement park type distribution)

2. Pre-place water and tea on tables and only have sodas and other beverages at the stations.
3. As opposed to fountain dispense only, have bins or refrigerators with canned and bottled beverages.

Each of these contingencies along with combinations was tested. Reduction in process time was achieved and is shown in Table 4, however another time constraint was detected. The new constraint related to Lodge porters servicing the tables.

Table 4: Results with Beverage Contingencies (Minutes)

\begin{tabular}{|l|c|c|c|}
\hline Process & Lower 95\% & Average & Upper 95\% \\
\hline Max Time & 46.73 & 49.37 & 52.02 \\
\hline Avg Time & 27.59 & 28.34 & 29.09 \\
\hline
\end{tabular}

It was assumed that each table, after use, would be cleaned by a porter prior to the next patron / group of patrons being seated. If a patron was forced to sit at a dirty table, dissatisfaction would result.

Based on the planned number of porters, volumes could overwhelm their ability to service tables. This created a queue in the simulation where patrons would have to wait for a "clean" table.

During the simulation runs it became evident that batches "slammed" into the Lodge based on large rooms releasing for the meal. This was noticed while watching the simulation run and observing the "wave" effect of large batches flowing through the simulation. The project team took a different approach at this point. The team began to look for ways to alleviate the batching problem.

The project team revisited the original assumptions and rules. An alternative approach was taken where inroom or outside Lodge catering would be allowed for large groups. The cooking facilities for the Lodge could still provide the food however the patrons would not come to the Lodge facility and beverages could be supplied via the multiple break areas in the Town Center.

Simulation trials where completed at differing levels of catering based on group size with the results shown in Table 5.

Table 5: Results of Multiple Catering Levels (Max Time in Process; Minutes)

\begin{tabular}{|l|c|c|c|}
\hline $\begin{array}{l}\text { Room Ca- } \\
\text { tering Level }\end{array}$ & Lower 95\% & Average & Upper 95\% \\
\hline$>=100$ & 47.14 & 49.33 & 51.51 \\
\hline$>=75$ & 42.05 & 43.61 & 45.16 \\
\hline$>=50$ & 40.57 & 41.57 & 42.58 \\
\hline$>=25$ & 37.17 & 37.62 & 38.06 \\
\hline
\end{tabular}

This data allowed the creation of the following guidelines and operating procedures on which to open the Town Center and Lodge. 
- Occupancy and group sizes will be monitored on a daily basis.

- When occupancy exceeds $20 \%$, beverages contingencies shall be invoked.

- When occupancy exceeds $40 \%$, in room catering shall be invoked for all groups of 50 or more.

Further, as shown in Table 6, the simulation delivered an expected number patrons to be catered as well as serviced in the Lodge which can be planned to achieve the required process time.

Table 6: Trial Result with Catering

\begin{tabular}{|l|c|c|c|}
\hline Process & Lower 95\% & Average & Upper 95\% \\
\hline Max Time & 40.57 & 41.57 & 42.58 \\
\hline Catering & & & \\
\hline \# People & 165 & 201 & 237 \\
\hline In Lodge & & & \\
\hline \# People & 468 & 496 & 524 \\
\hline
\end{tabular}

\section{SUMMARY AND CONCLUSION}

The Town Center experienced a "soft" opening or pilot period as part of the verify phase of Design for Six sigma. During the pilot, occupancies where monitored as well as queue times. Some adjustments to the original assumptions were required. However as the simulation predicted, the beverage stations became the time traps for the process. Contingencies tested in the simulation were invoked and the service levels to the customer maintained.

Senior management noted that the simulation allowed the project team to have contingencies in hand and to measure and predict the occurrence of the risk event. This allowed the Town Center and Lodge to open fully with delivery of all attributes and levels of performance identified as CTQs critical to satisfying its customers.

Finally the model was deployed to the management group overseeing the daily management of the town center. For the first few months of operation the managers would enter reserved occupancy level for the next day and run the simulation to detect possible issue.

During the first 6 months of operation, the Lodge operated in a flawless manner not only allowing patrons the ability to pass through in 45 minutes but in many cases satisfying requests where groups restricted lunch periods to 30 minutes. To this day, mitigation procedures and contingency plans identified and tested in the simulation are used every day.

In conclusion, this paper has presented how simulation was used in conjunction with six sigma to identify, assess, and mitigate a failure mode / risk event. This occurs during the design phase of DMADV process of Design for Six Sigma. Assumptions utilized in the simulation must be validate during the verify phase. However, the simulation itself can identify those assumptions which are critical to be measure and those which are not. The end result is a tool which allows a team to design a new process with a higher degree of predictability and reliability in delivering satisfaction to its customers.

\section{REFERENCES}

Goal / QPC. 2004. Design for six sigma memory jogger. Salem, New Hampshire: Goal / QPC

Simul8. 2004. Simul8 home page. Available via <http://www.simul8.com> [accessed January $\left.5^{\text {th }}, 2004\right]$

\section{AUTHOR BIOGRAPHY}

Michael Seifert, MBA, is a group manager in the process engineering team at Capital One. His specialties and interests are Operations Research, Six Sigma, LEAN, the Theory of Constraints and simulation. He received a BSEE from the United States Military Academy at West Point and his MBA from Ashland University in Ohio. He holds a CPIM certification from APICS (American Production and Inventory Control Society). Further he is certified as Black Belt in Six Sigma, as a LEAN practitioner and teacher, and as a Jonah in the Theory of Constraints. He is a member of APICS and INFORMS. His email address is $<$ Michael.seifertecapitalone.com>. 